\title{
Aerodynamic characteristics of a square cylinder with corner fins
}

\author{
Qiulei Wang, Qi Jiang, Gang Hu, Xiao Chen, Chao Li and Yiqing Xiao*
}

\author{
* Correspondence: xiaoyq@hit.edu. \\ cn \\ School of Civil and Environmental \\ Engineering, Harbin Institute of \\ Technology, Shenzhen 518055, \\ China
}

\begin{abstract}
This paper investigates the effect of fitting fins at the corners of a square cylinder on aerodynamic characteristics of the cylinder via wind tunnel tests and large eddy simulations (LES). Although it has been recognized that the corner fins have a remarkable effect on aerodynamic characteristics of a square cylinder, no study has been carried out to systematically evaluate this effect and reveal the underlying mechanism. Three types of corner fin configurations, i.e. fins fitted only to the leading corners, fins fitted only to the trailing corners, and fins fitted to both leading and trailing corners were studied. It was found that the corner fins significantly influence aerodynamic characteristics, such as mean drag coefficient, fluctuating lift coefficient, and vortex shedding of the cylinder. The influences of these corner fin configurations are very different. In general, the leading and trailing fins have an opposite effect on these characteristics. The mechanisms underlying these effects were clarified based on the flow regime visualized via LES. The interesting findings have practical significances not only for reducing aerodynamic forces and windinduced vibration of infrastructures, but also for enhancing wind-induced vibrationbased energy harvesting.
\end{abstract}

Keywords: Large eddy simulation, Square cylinder, Aerodynamic treatment, Corner modification, Corner fins

\section{Introduction}

Aerodynamic modification on bluff bodies such as square prism and circular cylinder has attracted extensive studies in the past decades due to its practical significance for either reducing wind-induced vibration of engineering structures or enhancing the vibration of wind energy harvesters.

The overwhelming majority of these studies concentrated on aerodynamic modifications to reduce wind-induced vibration for ensuring structural safety (Gao et al. 2017; Tang et al. 2019; $\mathrm{Xu}$ et al. 2014). The common strategies to achieve this goal include jet flow control (Chen et al. 2015), slotting corners (Kwok et al. 1988; Kwok and Bailey 1987), fitting solid or vented fins on corners (Kwok and Bailey 1987), chamfering corners (Kawai 1998; Kwok et al. 1988), rounding corners (Carassale et al. 2014; Zhang and Samtaney 2016), recessing corners (He et al. 2014; Kurata et al. 2009; Tse et al. 2009), smart façade (Ding and Kareem 2020; Hu et al. 2017, 2019b) and fitting a

(c) The Author(s). 2021 Open Access This article is licensed under a Creative Commons Attribution 4.0 International License, which permits use, sharing, adaptation, distribution and reproduction in any medium or format, as long as you give appropriate credit to the original author(s) and the source, provide a link to the Creative Commons licence, and indicate if changes were made. The images or other third party material in this article are included in the article's Creative Commons licence, unless indicated otherwise in a credit line to the material. If material is not included in the article's Creative Commons licence and your intended use is not permitted by statutory regulation or exceeds the permitted use, you will need to obtain permission directly from the copyright holder. To view a copy of this licence, visit http://creativecommons.org/licenses/by/4.0/. 
splitter plate in the wake (Nakamura et al. 1991). Kwok and Bailey (1987) found that using solid and vented fins on the corners of a square tower has significant effects on both alongwind and crosswind responses. Fitting small solid fins and vented fins causes an increased in the alongwind response, while reduction in crosswind response occurred only for a limited range of reduced wind velocities. This study only tested the model configuration with fins at all four corners. The corner fins could be an option for reducing wind loading on bridge pylons as sketched in Fig. 1a if it is designed properly. A tall building with corner fins has been built in Dongguan, China, as shown in Fig. 1b.

On the other hand, recently substantial efforts have been made for enhancing windinduced vibrations of bluff bodies to improve the efficiency of wind energy harvesters via aerodynamic modifications ( $\mathrm{Hu}$ et al. 2018, 2019a, c). For instance, two smalldiameter cylindrical rods were attached on two sides of a circular cylinder to successfully expand its aeroelastically unstable range to dramatically improve the efficiency of a vortex-induced vibration-based wind energy harvester (Hu et al. 2016c). Song et al. (2017) placed a splitter plate in the lee of a circular cylinder and the splitter plate plays a similar role as the two cylindrical rods do in the study of Hu et al. (2016c). Similarly, a tail fin was fitted on the leeward face of a bluff body to improve the performance of a galloping-based wind energy harvester by Noel et al. (2018). Another study to enhance the performance of the galloping-based wind energy harvester is to fit solid fins to the leading corners of a square cylinder (Hu et al. 2016a), as shown in Fig. 2. In this study, results from wind tunnel experiments show that fitting fins on the two leading corners significantly enlarges the galloping response and hence improves the generated wind power by $150 \%$. On the contrary, fitting fins on the two trailing edges suppresses the response, thereby reducing the output wind power. In addition, fitting fins on the four corners leads to a slight improvement on the performance of the harvester. Based on these observations, it is believed that fitting fins on corners of a square cylinder significantly influences aerodynamic characteristics of the square cylinder.

Although it has been recognized that fitting fins on the corners of a square cylinder has a remarkable effect on the cylinder's aerodynamic characteristics, no study has yet

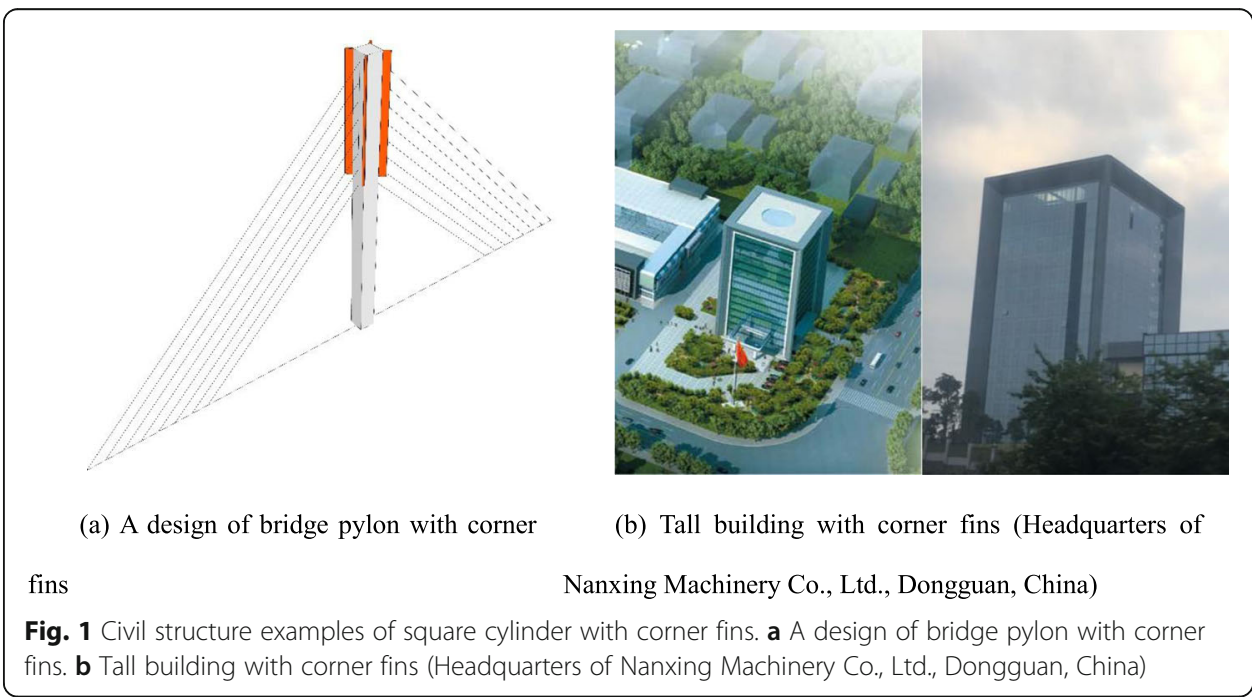




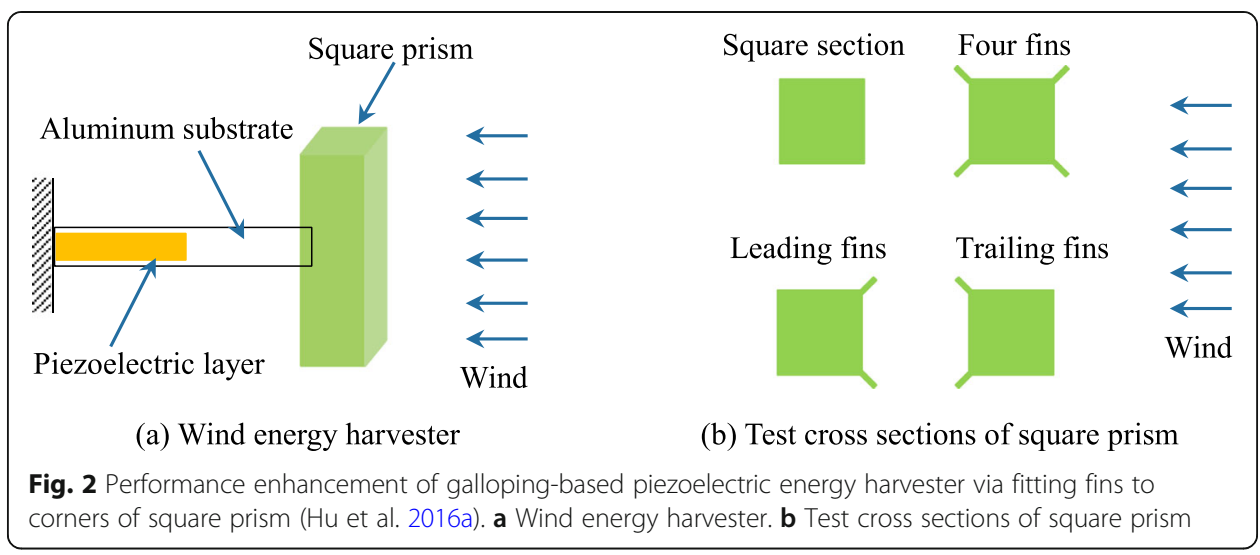

been conducted to examine the effect of corner fins on aerodynamic forces and flow filed of the square cylinder systematically. This study aims to evaluate this effect and clarify the related mechanism via wind tunnel tests and large eddy simulation (LES). Three types of fin configurations, i.e. fitting fins to the leading corners, fitting fins to the trailing corners, and fitting fins to both leading and trailing corners were studied.

\section{Experimental setup}

Force measurement tests were performed on a square cylinder with or without corner fins in an open-circuit wind tunnel with a $500 \mathrm{~mm}$ (width) $\times 380 \mathrm{~mm}$ (height) test section as shown in Fig. 3a. The cylinder was mounted on a multi-axis load cell (JR3, INC) and spanned the wind tunnel horizontally. Three types of fin configurations, i.e. fitting fins only to the leading corners, fitting fins only to the trailing corners, and fitting fins to both leading and trailing corners, plus a plain cylinder without fins were tested as given in Fig. 4. The three types of fin configurations were simply termed leading fins, trailing fins, and four fins hereafter. The cylinder had a width of $D=50.8 \mathrm{~mm}$; the fin length of $D / 6$, which is the optimal fin length for enhancing performance of a square prism-based wind energy harvester ( $\mathrm{Hu}$ et al. 2016a), was tested. The fins were fitted at the corners with an angle of $45^{\circ}$ from the oncoming flow direction. The tests were performed at a wind speed of $8 \mathrm{~m} / \mathrm{s}$, which corresponds to a Reynolds number of $2.69 \times$

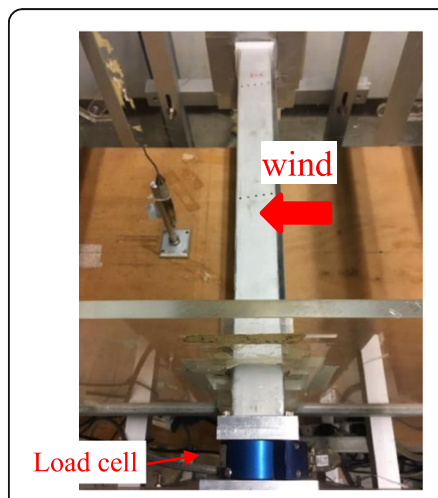

(a) Tests in the wind tunnel

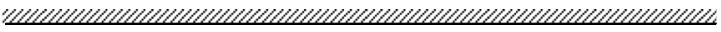

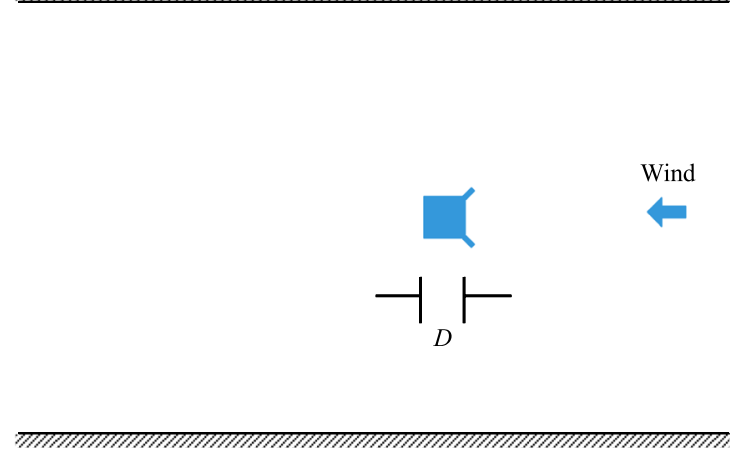

(b) Sketch of force measurement in the wind tunnel

Fig. 3 Force measurements of square cylinder with corner fins in the wind tunnel. a Tests in the wind tunnel. $\mathbf{b}$ Sketch of force measurement in the wind tunnel 


\begin{tabular}{|c|c|c|c|}
\hline $\begin{array}{l}\text { Plain cylinder } \\
\text { Fig. } 4 \text { Test cases v }\end{array}$ & $\begin{array}{l}\text { Leading fins } \\
\text { fin configurations }\end{array}$ & Trailing fins & Four fins \\
\hline
\end{tabular}

$10^{4}$. The oncoming flow with a turbulence intensity of $1.5 \%$ was imposed perpendicular to the windward face of the cylinder. The force measurements were taken at a sampling frequency of $400 \mathrm{~Hz}$ for a duration of 4000 vortex-shedding cycles.

The blockage ratios for the plain cylinder case and the cylinder with corner fin cases are $13.3 \%$ and $16.5 \%$ respectively, which exceed the critical value of $5 \%$ for avoiding the blockage effect (Holmes 2015). Numerous studies have been conducted to evaluate the blockage effect and have proposed correction methods. For instance, Maskell (1965) developed a correction theory based on the concept of a quasi-steady bubble-shaped wake. Modi and El-Sherbiny (1973) observed that Maskell's theory is valid for blockage ratios ranging from $5 \%$ to $10 \%$. Thus, they developed a correction formula for cylinders and flat plates with blockage ratios larger than 10\%. Raju and Singh (1975) suggested an empirical formula of the exponential form for two-dimensional cylinders of rectangular section in a smooth flow with side ratio ranging from 0 to 2 and the blockage ratio ranged from $7.5 \%$ to $24 \%$. All these studies were only concentrated on the correction of the steady force. Ota et al. (1994) proposed a correction formula for blockage effects on both steady and unsteady forces, e.g. mean drag coefficient, fluctuating drag coefficient and lift coefficient, and Strouhal number of two-dimensional bluff bodies such as a square cylinder. According to comparisons with the previous experimental data, the Ota's correction formula has been proved to be capable of estimating the wall effect quite accurately up to the blockage ratio of $20 \%$. The Ota's correction formula was, therefore, adopted to correct the blockage effect in the present study. The general correction formula is expressed as

$$
C_{F}=C_{F \infty} /\left(1-\xi_{F} h_{p} / h\right)
$$

where $\mathrm{C}_{\mathrm{F}}$ represents the coefficient of $F, \xi_{F}$ is the correction factor which has been provided by Ota et al. (1994), and the subscript $\infty$ denotes the value in an unbounded flow, $h_{p}$ is the projected height of cylinder, $h$ is the wind tunnel height and hence $h_{p} / h$ is the blockage ratio for the present test configuration.

\section{Numerical simulation configurations}

\subsection{Numerical methods}

Three-dimensional large eddy simulation (LES) turbulence model embedded in ANSYS FLUENT was used in the present study, since LES has been confirmed to accurately predict both mean and instantaneous flow fields around bluff bodies (Blocken 2014; Gousseau et al. 2013; Haque et al. 2014; Hu et al. 2015; Lam et al. 2012; Lam and Lin 2008; Li et al. 2013; Lim et al. 2009; Liu 2012; Tominaga et al. 2008; Yan and Li 2016; Zheng et al. 2012). Rodi (1997) compared LES and RANS model for flow around a square cylinder and a surface-mounted cube. He observed that RANS simulation 
severely underestimated the turbulence fluctuations while LES gave a significantly better prediction.

LES simulates large scale eddies by solving the filtered Navier-Stokes equations, in which the effect of small eddies is calculated using a subgrid scale (SGS) model. The present study chose the dynamic Smagorinsky-Lilly model as the SGS model. The flow is assumed to be Newtonian and incompressible. The filtered Navier-Stokes equations are given as

$$
\left\{\begin{array}{l}
\frac{\partial \bar{u}_{i}}{\partial t}+\frac{\partial \bar{u}_{i} \bar{u}_{j}}{\partial x_{j}}=-\frac{1}{\rho} \frac{\partial \bar{p}}{\partial x_{i}}+v \frac{\partial^{2} \bar{u}_{i}}{\partial x_{j} x_{j}}-\frac{\partial \tau_{i j}}{\partial x_{j}} \\
\frac{\partial \bar{u}_{i}}{\partial x_{i}}=0
\end{array}\right.
$$

where $i, j=1,2$ and $3 ; u_{1}, u_{2}$ and $u_{3}$ are the velocity components along $x_{1}$ (i.e. longitudinal direction), $x_{2}$ (lateral direction) and $x_{3}$ (vertical direction) of the Cartesian coordinate system, respectively. The overbar denotes the filtering operator. $\rho$ and $v$ are air density and kinematic viscosity respectively. $\bar{p}$ is the pressure and $\tau_{i j}$ is the components of the SGS stress tensor which is defined as

$$
\tau_{i j}=\overline{u_{i} u_{j}}-\bar{u}_{i} \bar{u}_{j} .
$$

Based on the Boussinesq hypothesis, the subgrid-scale turbulent stresses are computed as

$$
\tau_{i j}-\frac{1}{3} \tau_{k k} \delta_{i j}=-2 \mu_{t} \bar{S}_{i j}
$$

where $\bar{S}_{i j}$ is the strain rate tensor for the resolved velocities and $\mu_{t}$ is the subgrid-scale turbulent viscosity. The Smagorinsky-Lilly model was adopted to calculate $\mu_{t}$ as:

$$
\mu_{t}=L_{s}^{2}|\bar{S}|
$$

where $|\bar{S}|=\sqrt{2 \bar{S}_{i j} \bar{S}_{i j}}$ is the characteristic filtered rate of strain and $L_{s}=\min \left(\kappa d, C_{s}\right.$ $\left.V_{c}^{1 / 3}\right)$ is the mixing length for the subgrid scales calculated according to $\kappa$ the von Karman constant, $d$ the distance to the closest wall, $V_{c}$ the volume of the computational cell and $C_{s}$ the Smagorinsky coefficient.

The finite volume method was adopted to solve the unsteady incompressible NavierStokes equation. The PISO scheme was used to solve the pressure-velocity coupling. The bounded second order implicit scheme was selected for time discretization; the second order scheme was used for spatial discretization of pressure; and the bounded central differencing was employed for spatial discretization of the momentum equations. For the unsteady simulation, time step is another important parameter. The time step $(\Delta t)$ of $2 \times 10^{-5} \mathrm{~s}$ was selected after testing a few shorter and longer time steps, and it ensured the Courant-Friedrichs-Lewy (CFL) number less than 1 in the computational domain. Each simulation was initialized with the solution of a preceding RANS simulation for fast convergence of computation. For all simulations, more than 1000 non-dimensional time steps, corresponding to approximately 133 vortex-shedding cycles that is much larger than the number of cycles adopted in the previous studies summarized by Rodi et al. (1997) and Voke (1997), were taken to assure reliable results. 


\subsection{Computational domain and mesh arrangement}

The width $(D)$ of the cross section was $24 \mathrm{~mm}$, and the length of the square cylinder was $4 D$, which has been widely used in the literature (Nakayama and Vengadesan 2002; Rodi et al. 1997; Sohankar et al. 1999; Voke 1997). The distance between the windward face of the cylinder and the inlet was $8 D$. The lateral boundary was $5 D$ away from the lateral face, which is identical to that adopted by Sakamoto et al. (1993) and larger than $4 D$ used by Breuer et al. (2000). To allow flow re-development behind the wake region, the outlet boundary was set $17 D$ away from the leeward face in terms of the previous studies (Rodi et al. 1997; Sohankar et al. 1999).

At the inlet boundary, a smooth flow with a wind speed of $U=12 \mathrm{~m} / \mathrm{s}$ was imposed, leading to a Reynolds number of $1.90 \times 10^{4}$, which is lower than that in the wind tunnel tests. For the square prisms with or without corner fins, this type of bluff body with sharp edges is not sensitive to the Reynolds number (Holmes 2015). Therefore, the difference in the Reynolds number between wind tunnel tests and LES studies is believed to be unable to cause considerable discrepancy in the results of aerodynamic characteristics. The two lateral boundaries were defined as a symmetry boundary condition that was used to model zero-shear slip walls in viscous flows. A pair of translational periodic conditions were enforced on the top and bottom of the computational domain. A nonslip wall boundary condition was imposed on the surfaces of the cylinder. Zero-gauge pressure was adopted at the outlet.

Hexahedral meshes were used for the whole computational domain as shown in Fig. 5. To consider the influence of grid resolution on the numerical simulation, three systematically and substantially refined grids (i.e., GS1, GS2 and GS3) for the plain square cylinder case were tested prior to launching the final numerical simulations. The specifications of the grids used are given in Table 1. Comparisons of mean pressure coefficients around the square cylinder between previous studies and the present

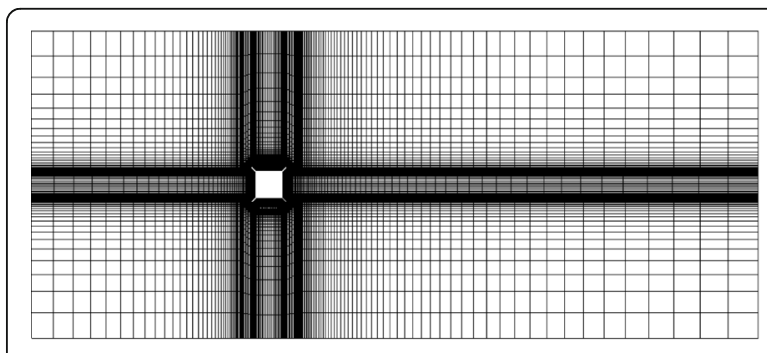

(a) Sectional view of the grids

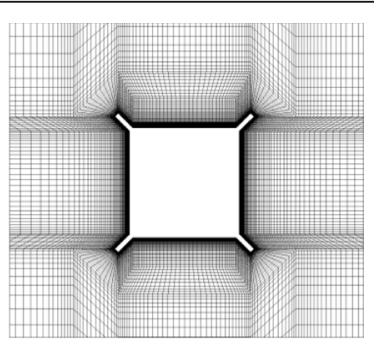

(b) Grids around the cylinder

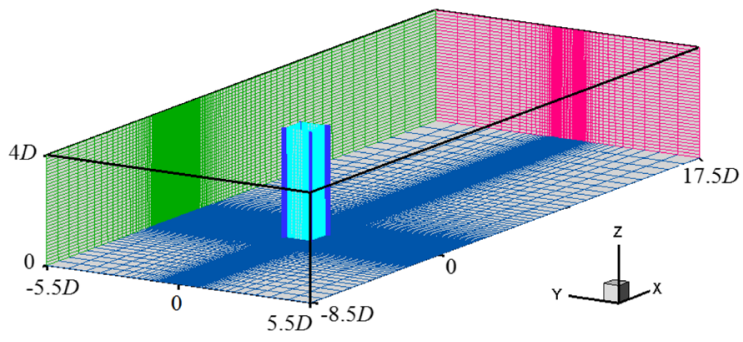

(c) $3 \mathrm{D}$ view of the grids

Fig. 5 Views of grids for a square cylinder with fins at four corners. a Sectional view of the grids. b Grids around the cylinder. c 3D view of the grids 
Table 1 Grid schemes for grid independence tests

\begin{tabular}{llllll}
\hline $\begin{array}{l}\text { Grid } \\
\text { schemes }\end{array}$ & $\begin{array}{l}\text { Grid } \\
\text { number }\end{array}$ & $\operatorname{Max}\left(\boldsymbol{y}^{+}\right)$ & Mean $\left(\boldsymbol{y}^{+}\right)$ & $\begin{array}{l}\text { Minimum grid size } \\
(\mathbf{m m})\end{array}$ & $\begin{array}{l}\text { Number of grids in the span } \\
\text { length }\end{array}$ \\
\hline GS1 & $2.5 \times 10^{5}$ & 1.37 & 0.45 & 0.02 & 24 \\
GS2 & $5.0 \times 10^{5}$ & 1.18 & 0.32 & 0.02 & 34 \\
GS3 & $1.0 \times 10^{6}$ & 1.47 & 0.39 & 0.02 & 41 \\
\hline
\end{tabular}

numerical simulations are presented in Fig. 6; part of the numerical simulation results are compiled in Table 2 with data from previous studies. Evidently, the mean pressure coefficients on the four sides have good agreement between the grid schemes GS2 and GS3 and these coefficients are also consistent with the results in the previous studies (Bearman and Obasaju 1982; Cao and Tamura 2016; Otsuki et al. 1978). However, the simulation based on the GS1 scheme showed a worse prediction for the mean pressure coefficients on the leeward face.

The drag, lift coefficients and Strouhal number of the square cylinder obtained from the three grid schemes are compared with previous studies in Table 2. The mean drag coefficient and the Strouhal number are defined as

$$
C_{d}=\frac{F_{d}}{1 / 2 \rho U^{2} D}, \quad C_{l}=\frac{F_{l}}{1 / 2 \rho U^{2} D}, \quad S_{t}=\frac{f_{v} D}{U}
$$

where $F_{d}$ and $F_{l}$ are the drag and lift forces of the cylinder respectively; $f_{v}$ is the vortex shedding frequency; $D$ is the width of the cross section and $U$ is the oncoming flow velocity set at the inlet boundary condition. The comparisons with present experimental results and previous studies' results show that GS2 and GS3 gave more accurate predictions on drag and lift coefficients than GS1. The improvement attributed to the increase in the grid cell from GS2 to GS3 is not very distinct. The grid scheme GS2 was, therefore, selected for the final computation to save computation time. It should be noted that although GS2 was a grid scheme for the plain cylinder, the same grid size

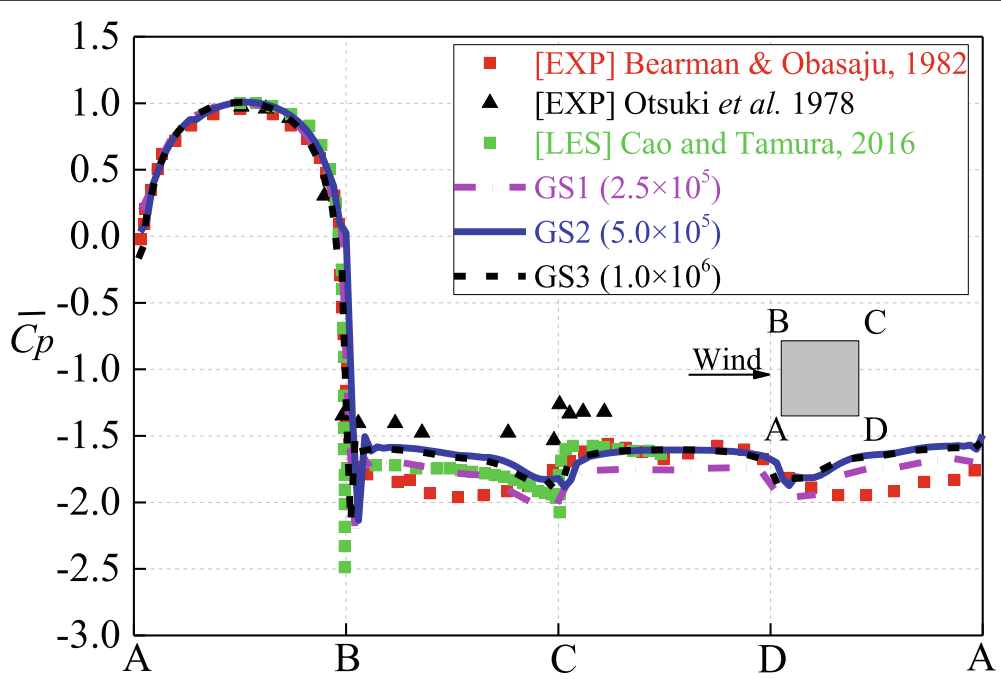

Fig. 6 Comparisons of mean pressure coefficients around the square cylinder between previous studies and the present numerical simulations 
Table 2 Comparisons of force coefficients between previous studies and present numerical simulations

\begin{tabular}{lllll}
\hline Data from previous studies & Reynolds number & $C_{l}^{R M S}$ & $\overline{C_{d}}$ & $\boldsymbol{S}_{\boldsymbol{t}}$ \\
\hline Experimental results: & & & & \\
$\quad$ Lyn et al. (1995); Lyn and Rodi (1994) & $2.14 \times 10^{4}$ & - & 2.1 & 0.132 \\
Lee (1975) & $1.76 \times 10^{5}$ & - & 2.05 & 0.122 \\
$\quad$ Hangan (1996) & $2.20 \times 10^{4}$ & 0.95 & 2.09 & 0.123 \\
Present experimental results & $2.69 \times 10^{4}$ & 1.52 & 2.30 & 0.115 \\
Present simulation results & & & & \\
GS1 $\left(2.5 \times 10^{5}\right)$ & $1.90 \times 10^{4}$ & 1.62 & 2.52 & 0.121 \\
GS2 $\left(5.0 \times 10^{5}\right)$ & $1.90 \times 10^{4}$ & 1.37 & 2.37 & 0.122 \\
GS3 $\left(1.0 \times 10^{6}\right)$ & $1.90 \times 10^{4}$ & 1.37 & 2.36 & 0.120 \\
\hline
\end{tabular}

distribution for the whole domain was also used for all other cylinders with fins in the present study.

\subsection{Simulation cases}

The simulation cases are identical with the cases tested in the wind tunnel. The grid information based on grid scheme GS2 for these cases is shown in Table 3. The existence of the fins reasonably increases the total number of grids. The mean $y^{+}$values for all cases approximately ranged from 0.32 to 0.4 . Only a little proportion of $y^{+}$plus values were higher than 1 , the suggested threshold for LES.

\section{Results and analyses}

\subsection{Mean pressure coefficients}

Mean pressure coefficients $\left(\overline{C p}=\left(p-p_{\infty}\right) /\left(1 / 2 \rho U^{2}\right)\right)$ around the cylinder surface at midspan, i.e. $z=2 D$, for the four cases are compared in Fig. 7. In the windward face $(A B), \overline{C p}$ at the stagnation point, i.e. the middle of the windward side, is justifiably slightly lower than 1.0 for all four cases. From the stagnation point to the two edges, $\overline{C p}$ gradually decreases, especially for the cases without leading fins, i.e., the plain cylinder case and the trailing fin case. By contrast, the decrease in the cases with leading fins, i.e. the leading fin case and the four fin case, is much less remarkable. At points $a$ and $b, \overline{C p}$ is still very large, and only slightly smaller than that at the stagnation point, while it is much larger than in the cases without leading fins. $\overline{C P}$ on the leading fins dramatically drops from the base to the tip, i.e. from $a$ to $A$ and from $b$ to $B$.

For the two side faces $(A D$ and $B C)$, their pressure coefficients are negative due to flow separation, and the distributions on the two side faces are symmetrical in a sensible way. Overall, $\overline{C p}$ on the side faces of the trailing fin case has the largest value. The value of the

Table 3 Grid information for simulation cases with different fin locations

\begin{tabular}{lllll}
\hline Cases & Total Grid Number & $\operatorname{Max}\left(\mathbf{y}^{+}\right)$ & Mean $\left(\boldsymbol{y}^{+}\right)$ & Minimum grid size $(\mathbf{m m})$ \\
\hline Plain cylinder & $5.0 \times 10^{5}$ & 1.18 & 0.32 & 0.02 \\
Leading fins & $7.0 \times 10^{5}$ & 1.40 & 0.34 & 0.02 \\
Trailing fins & $7.0 \times 10^{5}$ & 1.27 & 0.34 & 0.02 \\
Four Fins & $8.3 \times 10^{5}$ & 2.09 & 0.40 & 0.02 \\
\hline
\end{tabular}




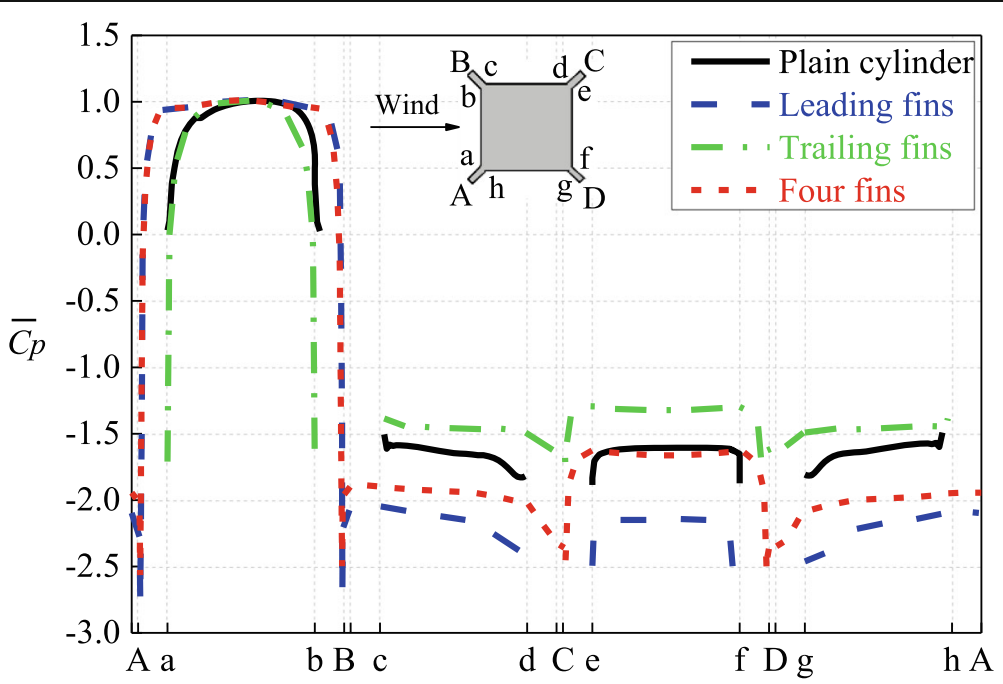

Fig. 7 Mean pressure coefficients around the cylinder for four cases

plain cylinder is more negative than the trailing fin case. Therefore, the existence of trailing fins reduces the suction on the side face. On the contrary, the two cases with leading fins, i.e. the leading fin case and the four fin case, have much lower $\overline{C p}$ than the plain cylinder, which implies that the leading fins play a role to enhance the suction. Furthermore, the case with pure leading fins has more negative $\overline{C p}$ than the case with four fins, which further confirms the role of the trailing fins to reduce suction on the side face. Consequently, it is concluded that the leading fins enhance suction on the side face, whereas the trailing fins are able to reduce the suction over there.

For the leeward face $(C D)$, the trailing fin case has much less suction, while the leading fin case exhibits significantly higher suction. Similar to the observations on the side face, it is believed that the trailing fins serve to weaken the suction on the leeward face, whereas the leading fins play a role to amplify the suction. Their effects on suction counteract each other in the four fin case, leading to suction that is generally consistent with the plain cylinder. For easy reference, the mean base pressure coefficients for the four cases are given in Table 4.

In summary, the leading fins enhance the suction on both side faces and leeward face, while the trailing fins play a role to weaken the suction on these faces. This interesting finding provides an effective aerodynamic strategy to control the surface pressure of square- or rectangular-sectioned bluff bodies, such as reduce the suction on side and leeward faces of tall buildings to safeguard the façade under strong wind.

\subsection{Force coefficients and vortex shedding characteristics}

Mean drag coefficients $\left(\overline{C_{d}}\right)$, Strouhal numbers $\left(S_{t}\right)$, and RMS lift coefficients $\left(C_{l}^{R M S}\right)$ from LES and wind tunnel tests are compiled in Table 5; comparisons between these

Table 4 Mean base pressure coefficients for four cases

\begin{tabular}{lllll}
\hline Case & Plain cylinder & Leading fins & Trailing fins & Four Fins \\
\hline$C_{p b}$ & -1.61 & -2.15 & -1.32 & -1.66 \\
\hline
\end{tabular}


Table $\mathbf{5}$ Lift, drag coefficients, and Strouhal numbers of the four cases from LES

\begin{tabular}{|c|c|c|c|c|c|c|c|c|c|}
\hline \multirow[t]{2}{*}{ Cases } & \multicolumn{3}{|l|}{$\overline{C_{d}}$} & \multicolumn{3}{|l|}{$S_{t}$} & \multicolumn{3}{|l|}{$C_{l}^{R M S}$} \\
\hline & LES & EXP & Difference & LES & EXP & Difference & LES & EXP & Difference \\
\hline Plain cylinder & 2.37 & 2.30 & $3.0 \%$ & 0.122 & 0.115 & $6.1 \%$ & 1.37 & 1.52 & $9.8 \%$ \\
\hline Leading fins & 3.68 & 3.46 & $6.3 \%$ & 0.101 & 0.090 & $12 \%$ & 2.25 & 2.68 & $16 \%$ \\
\hline Trailing fins & 2.01 & 2.02 & $0.5 \%$ & 0.118 & 0.110 & $7.2 \%$ & 0.87 & 1.01 & $14 \%$ \\
\hline Four Fins & 3.06 & 3.08 & $0.6 \%$ & 0.093 & 0.090 & $3.3 \%$ & 1.93 & 2.26 & $15 \%$ \\
\hline
\end{tabular}

two sets of data are made. The differences of $\overline{C_{d}}$ predicted by LES and wind tunnel tests (abbreviated to EXP) are within 6.3\% for the four cases, which indicates that LES provides a pretty good prediction to the mean drag coefficients. Likewise, the differences of $S_{t}$ from LES and wind tunnel tests are within $7.2 \%$ for all the cases except the leading fin cases, of which the difference is $12 \%$. By contrast, the differences of $C_{l}^{R M S}$ between the two sets of data are relatively larger and the maximum reaches $16 \%$ for the leading fin case. These relative large differences may be induced by the oncoming flow turbulence with a turbulence intensity of $1.5 \%$ in the wind tunnel tests. Overall, the LES provides decent predictions on the aerodynamic properties of the cylinders.

Differences of these parameters between the cases with fins and the plain cylinder are expressed in percentage of that of the plain cylinder in Fig. 8. The two cases with leading fins, i.e. the leading fin case and the four fin case, have much greater $\overline{C_{d}}$ than the plain cylinder; the leading fins dramatically increase $\overline{C_{d}}$ by approximately $50 \%$ and $30 \%$ in the two cases respectively. These findings can be verified by previous study. Kwok and Bailey (1987) reported that fitting fins to the four corners increased the drag force and mean alongwind response of a tall square tower compared with a plain square tower, which is consistent with the present results.

On the contrary, the trailing fins in the trailing fin case reduce $\overline{C_{d}}$ by about $15 \%$, which agrees with the observation of galloping response reduction resulting from fitting fins onto the two trailing corners of a square cylinder in Hu et al. (2016a). The increase

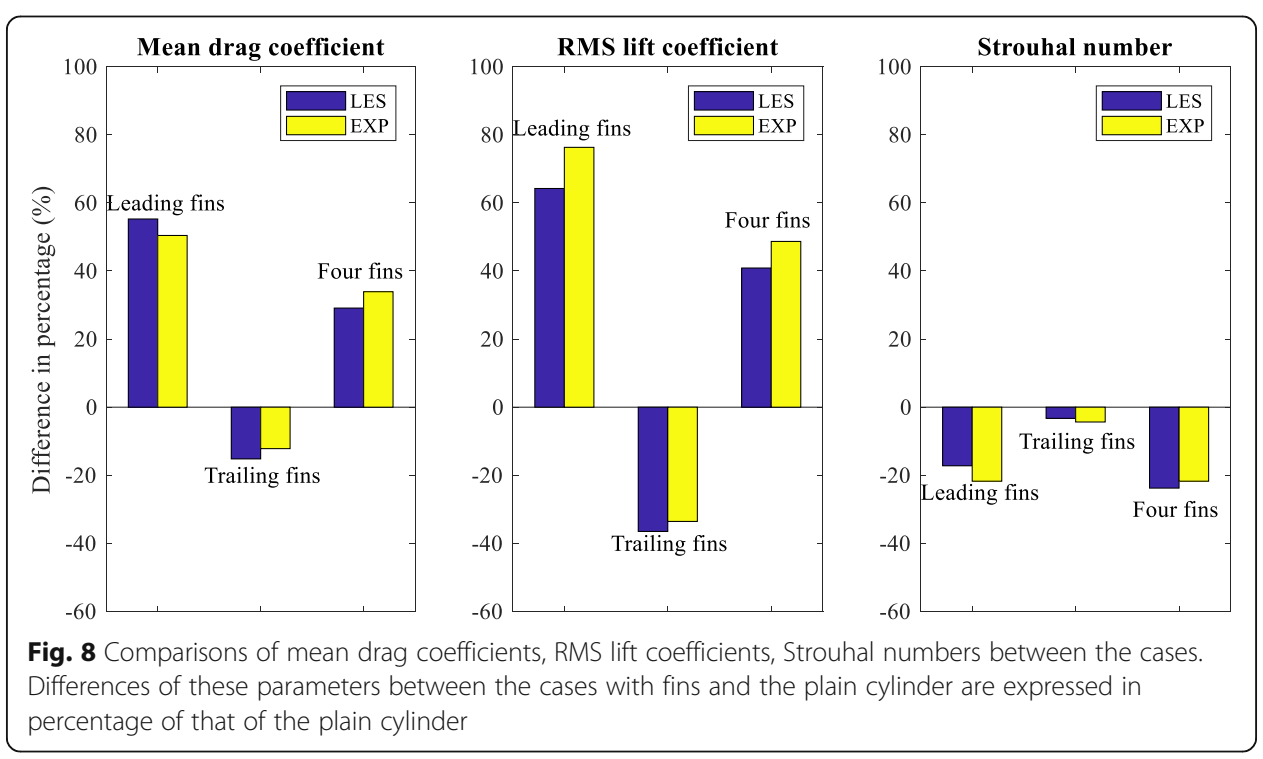


by $30 \%$ in $\overline{C_{d}}$ for the four fin case is considered a resultant effect of leading fins and trailing fins. Overall, the leading fins can increase mean drag substantially, while the trailing fins reduce mean drag.

Similar to their respective changes in $\overline{C_{d}}$, the leading fin case has a much larger $C_{l}^{R M S}$ with an increase of approximately $70 \%$, and the four fin case has an increase of about $45 \%$. However, the trailing fin case has a reduction of about $36 \%$. Therefore, it is believed that the leading fins increase the RMS lift coefficient while the trailing fins decrease the coefficient, and both changes are remarkable.

Power spectra of the lift forces obtained by LES are given in Fig. 9 and the spectra reflect the interaction intensity of the shear layer with the side face. The spectrum of the plain cylinder agrees well with that in Murakami et al. (1999) within the concerned frequency range. The Strouhal numbers $\left(S_{t}\right)$ listed in Table 5 are extracted from these spectra. All three types of fin configurations reduce $S_{t}$, which implies that the fins slow down the vortex shedding process. Specifically, the Strouhal number for the trailing fin case is slightly lower than that of the plain cylinder, as shown in Fig. 8. However, the spectrum energy, represented by the peak values in Fig. 9, is obviously lower than of the plain cylinder. By contrast, both the leading fin case and the four fin case have a much smaller Strouhal number, approximately $20 \%$ lower than that of the plain cylinder, whereas the spectrum energy is higher than that of the plain cylinder. This observation is consistent with the finding reported by Kwok and Bailey (1987). In their study, a comparison of the lift force spectrum between the plain square tower and the square tower with four fins was made. The comparison also shows that the square tower with four fins exhibits a lower $S_{t}$ but higher spectrum energy, which further verifies the reliability of the current LES study. In addition, in Fig. 9, the spectrum energy of the leading fin case is obviously larger than that of the four fin case. Apparently, the

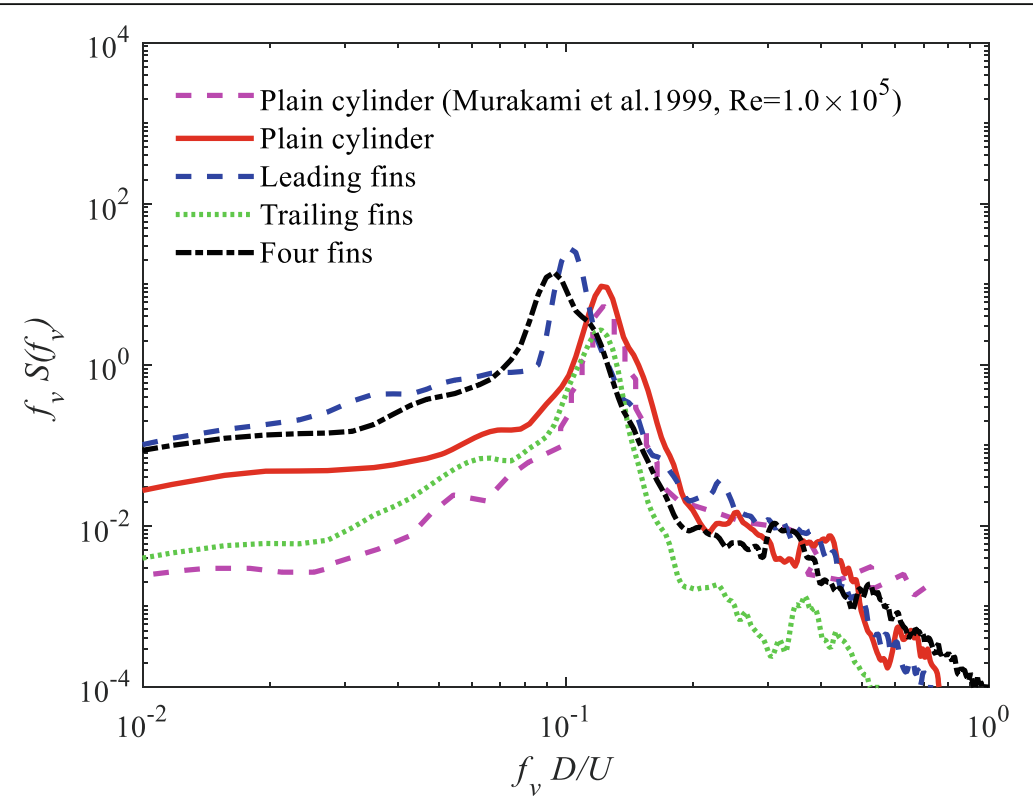

Fig. 9 Power spectra of lift forces of the cylinders for the four cases. The spectrum of the plain cylinder is compared with that in Murakami et al. (1999) 
leading fins lead to a lower frequency but higher spectrum energy, while the trailing fins result in a slightly lower frequency and lower energy.

\subsection{Flow pattern around the cylinders}

The considerable effects of corner fins on the aerodynamic characteristics of a square cylinder have been detailed above. The variations in the aerodynamic characteristics are associated with alterations in flow pattern around the cylinder. The flow patterns are discussed in this section to clarify the related mechanism.

\subsubsection{Plain cylinder}

Time-averaged streamlines around the cylinder are given in Fig. 10. For the plain cylinder, the flow begins to separate at the two sharp leading corners and forms two recirculation zones beside the two side faces. A pair of recirculation zones are also identified in the near wake. The pressure inside each recirculation zone is negative as shown in Fig. 11 and it therefore leads to negative pressures on both the side faces and the leeward face (see Fig. 7).

\subsubsection{Leading fin case}

The magnitude of the negative pressure on the side and leeward faces is highly dependent on the shape and dimension of the recirculation zones (Bearman and Trueman 1972; Hu et al. 2016b; Huot et al. 1986; Tombazis and Bearman 1997; Kurata et al. 2009). Compared to the flow pattern beside the side face of the plain cylinder, the recirculation zone for the leading fin case is more complicated. The zone consists of

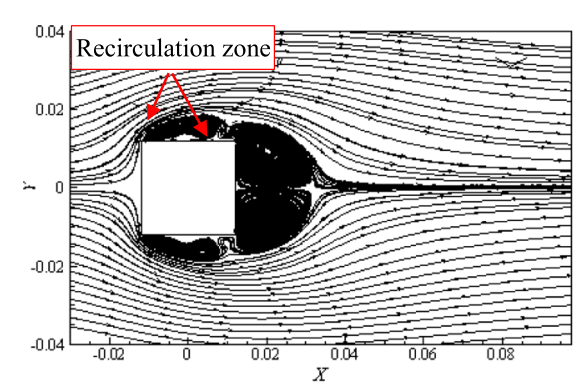

(a) Plain cylinder

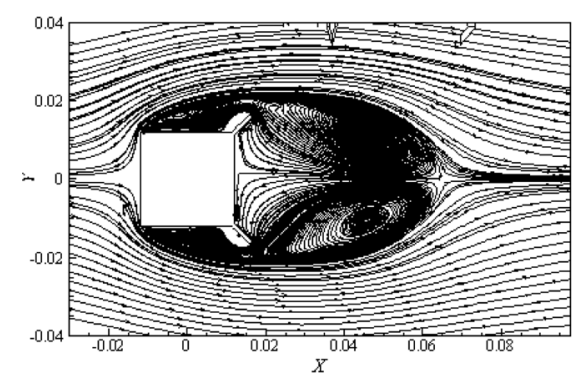

(c) Trailing fins

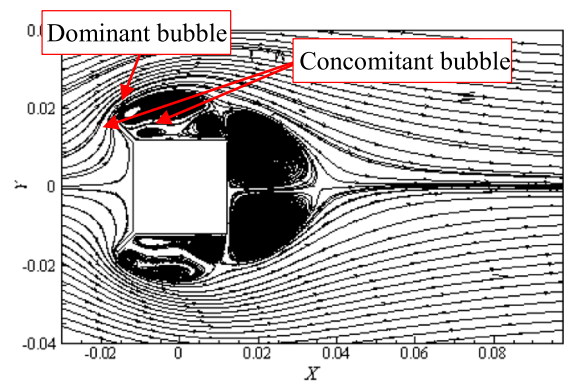

(b) Leading fins

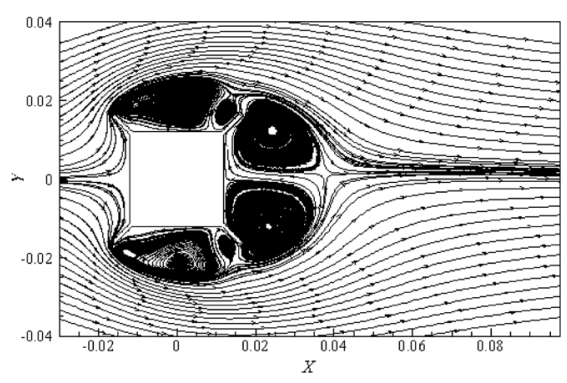

(d) Four fins

Fig. 10 Time-averaged streamlines for four cases. a Plain cylinder. b Leading fins. c Trailing fins. d Four fins 


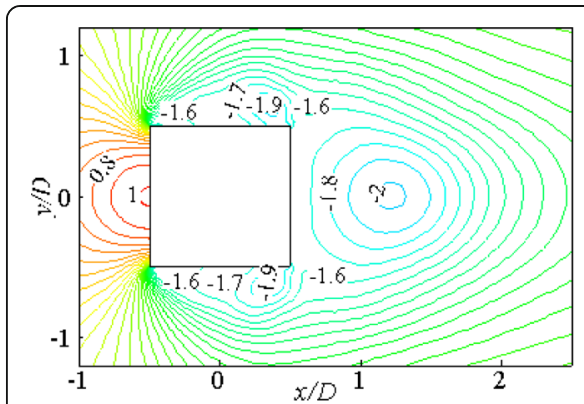

(a) Plain cylinder

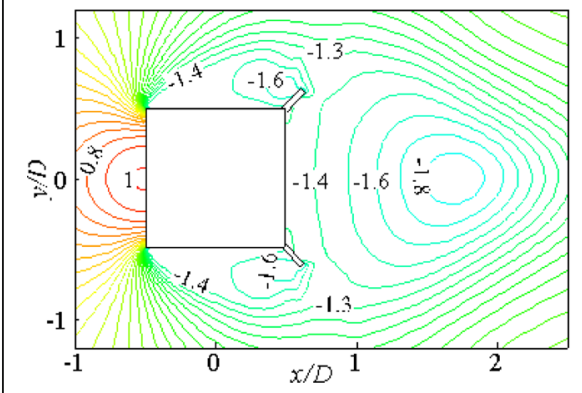

(c) Trailing fins

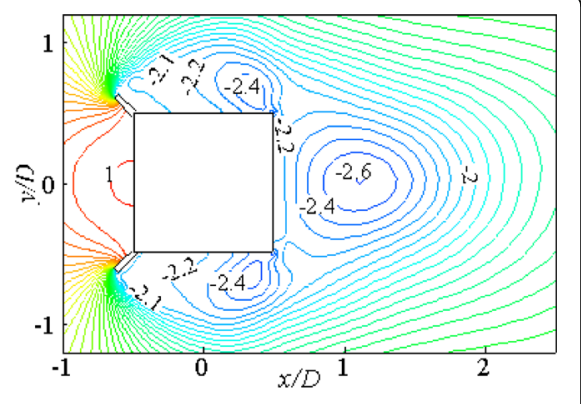

(b) Leading fins

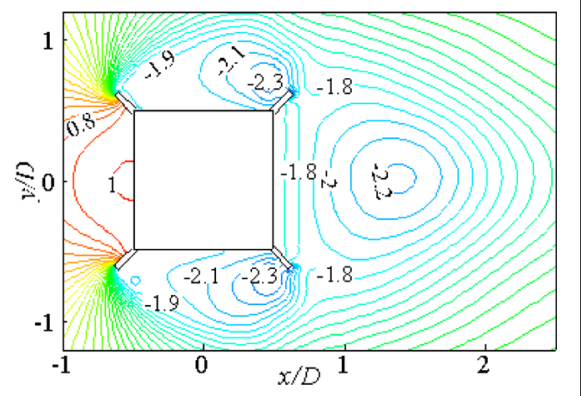

(d) Four fins

Fig. 11 Time-averaged pressure coefficient distribution. a Plain cylinder. b Leading fins. c Trailing fins. d Four fins

three recirculation bubbles, one dominant big bubble and two concomitant small bubbles. The dominant bubble is larger than the bubble beside the side face of the plain cylinder and its location is further from the side face. As a result, the curvature of the separated shear layer is greater than that of the plain cylinder, which can also be observed clearly in the instantaneous spanwise vorticity pattern in Fig. 12. In Fig. 12b, the shear layer separated from the leading fins and has an obvious reattachment/interaction with the side face, which leads to a large curvature of the shear layer. As stated by Laneville et al. (1975), the suction depends on the curvature of the shear layer; the stronger the curvature, the larger the suction. Therefore, the larger curvature of the shear layer for the leading fin case leads to the larger suction on the side face than that for the plain cylinder as shown in Figs. 7 and 11.

The dimension of the wake recirculation zone, i.e. width and length, is directly related to the base pressure behind a two-dimensional bluff body (Bearman 1965, 1967; Tombazis and Bearman 1997). Moreover, the base pressure is inversely associated with the drag of a bluff body (Bearman and Trueman 1972). The drag coefficient is proportional to the wake width, while inversely proportional to the length of the recirculation zone, i.e. the vortex formation length (He et al. 2014; Hu et al. 2016a, b; Tamura and Miyagi 1999; Ueda et al. 2009). Meanwhile, the fluctuating lift coefficient is also inversely proportional to the length of the recirculation zone (Lam and Lin 2008). Because a longer recirculation zone in the wake indicates that the rollup of shear layer in the wake is farther from the buff body, hence the effect of the shear layer rollup on the side face is weaker, which leads to a lower fluctuating lift coefficient. Although the difference in the vortex formation length between the plain cylinder case and the leading 


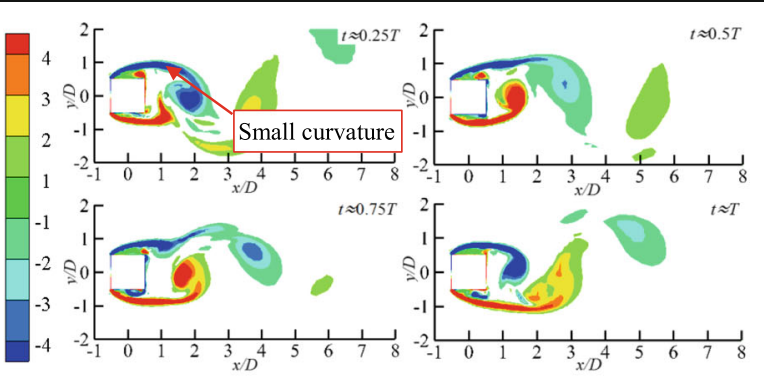

(a) Plain cylinder

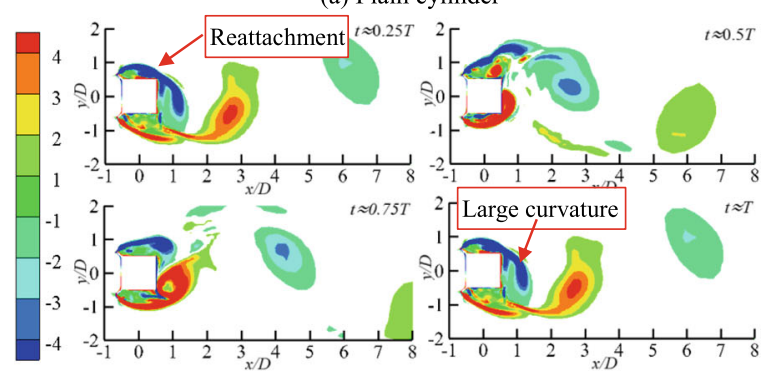

(b) Leading fins

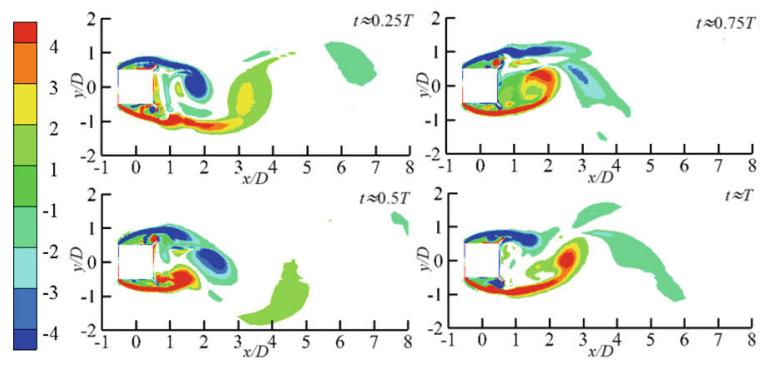

(c) Trailing fins

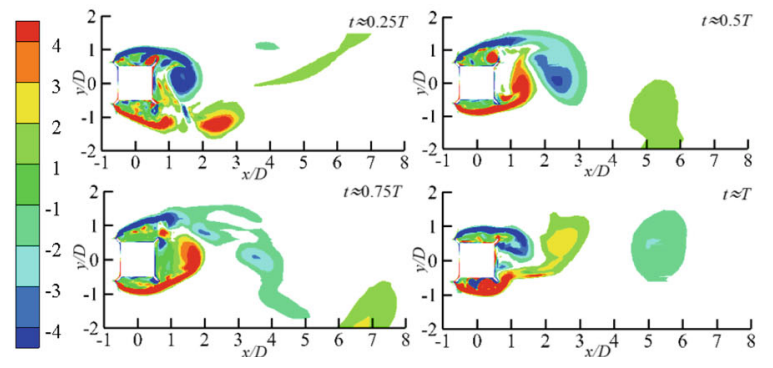

(d) Four fins

Fig. 12 Normalized instantaneous spanwise vorticity distributions during one period for four cases. a Plain cylinder. b Leading fins. $\mathbf{c}$ Trailing fins. $\mathbf{d}$ Four fins

fin case is tiny (approximately 11\%), as shown in Fig. 10, the wake width of the leading fin case is clearly larger than that of the plain cylinder case. The larger wake width, actually a stronger curvature of the shear layer in the wake (see Fig. 12b), leads to a lower base pressure as shown in Fig. 11 and Table 4. Meanwhile, the pressure on the windward face of the leading fin case is larger as demonstrated in Fig. 7. Therefore, the much larger drag coefficient in the leading fin case than the plain cylinder case is a result of the lower base pressure and the larger pressure on the windward face.

The normalized instantaneous spanwise vorticity distributions at four instants during one period are given in Fig. 12. For the leading fin case, the separated shear layer has a 
stronger interaction with the side faces compared to the plain cylinder case. The curvature of the shear layer is remarkably larger, which is consistent with the observations in Fig. 10. The much stronger interaction results in the larger fluctuating lift coefficients on the side face as given in Fig. 8 and Table 5. Furthermore, the stronger interaction implies a more intense interruption in the vortex shedding process and hence a lower Strouhal number. Meanwhile, the stronger interaction leads to a higher energy in the lift force spectrum in Fig. 9.

\subsubsection{Trailing fin case}

As shown in Fig. 10, the streamline passing through the cylinder with trailing fins is quite different from that of other cases. The flow begins to separate at the leading corners, forms a recirculation zone beside the side face, then goes over the trailing fin and forms a very large recirculation zone in the wake. The shear layer is slightly less curved than that of the plain cylinder (also can be seen in Fig. 12) because the trailing fins push it away from the cylinder. The slightly less curved shear layers lead to slightly less negative pressures on/beside the side faces and the leeward face as given in Figs. 7 and 11. The less negative pressures on the leeward face along with the generally consistent pressure distribution on the windward face leads to a $15 \%$ decrease in drag coefficient as presented in Fig. 8. Referring to the recirculation zone dimension, the lower drag coefficient for the trailing fin case can also be inferred. Apparently, the wake recirculation zone is dramatically elongated by the trailing fins (see Fig. 10). As mentioned above, the drag coefficient is inversely proportional to the length of the wake recirculation zone. Therefore, the longer recirculation zone results in a lower drag coefficient. The less fluctuating lift coefficient can also be attributed to the elongated wake recirculation zone. The spanwise vorticity distributions in four instants shown in Fig. 12c indicate that the trailing fins push the separated shear layer away and weakens its interaction with the side faces. The weaker interaction causes a lower spectrum peak in the lift force spectrum.

\subsubsection{Four fin case}

Compared with the cylinder with only leading fins in Figs. 10 and 12, the shear layer for the cylinder with four fins is less curved due to the presence of the two trailing fins. Therefore, the pressures on/beside the side faces and the leeward face are less negative than those for the cylinder with only leading fins. However, the pressures are still lower than those for the plain cylinder. As a result, the drag coefficient is lower than that of the leading fin case but higher than that of the plain cylinder. The rollup of the shear layer occurring in the near wake is closer to the leeward face of the cylinder compared with the plain cylinder case as shown in Fig. 12, which induces a larger fluctuating lift force in the four fin case.

\section{Discussions}

The above sections have demonstrated that the fins fitted at corners of square cylinder have a remarkable influence on the aerodynamic properties including surface pressure, drag force, lift force, vortex shedding strength and frequency of the cylinder. The trailing fins suppress suctions on side faces and leeward face, and also reduce not only drag 
force but also fluctuating lift force. As a result, the trailing fin configuration is desirable for the wind-resistant design of bridge pylons and tall buildings. However, the natural wind direction is variable. If two fins are fixed at two edges of bridge pylons and tall buildings, there are three possible scenarios due to change in wind direction: the leading fin configuration, the trailing fin configuration, one fin at leading edge and the other one at trailing edge. Therefore, fixing two fins at two edges of bridge pylons and tall buildings is very impractical. Nevertheless, smart controlling the position of the fins in terms of wind direction by using the cutting edge artificial intelligence techniques (Bao and Li 2020; Hu et al. 2020; Hu and Kwok 2020; Jin et al. 2018; Li et al. 2018), more specifically reinforcement learning techniques (Fan et al. 2020; Rabault et al. 2019), provides a possibility to take advantage of the merits of the trailing fin configuration. In detail, the fins are installed inside tall buildings at four corners but can be protruded from the building, as shown in Fig. 13a. According to the wind direction, which can be monitored by using an anemometer at the building top, the fins at the two trailing edges are protruded from the building, while the other two fins are kept inside the building, which forms the trailing fin configuration. Another potential application of the trailing fin configuration is to reduce the hydrodynamic drag of bridge pier in a river. Compared to the application to reducing wind-induced force acting on bridge pylons and tall buildings, this application is more straightforward because the flow direction in a river is fixed, as shown in Fig. 13b.

On the other hand, in practical applications, such as bridge towers and high-rise buildings, the vortex-induced vibration (VIV) has three-dimensional characteristics, and the VIV along the spanwise direction is not completely synchronous (Ricciardelli 2010; Li et al. 2015, 2016). In particular for a slender structure, the spanwise distribution of aerodynamic load on it is very important. If it is not fully understood, the prediction of overall aerodynamic force will be affected. Therefore, it is necessary to further study the spanwise correlation analysis and surface fluctuating wind pressure distribution of square column with fins, and verify the results of flow field simulation through PIV wind tunnel test.

\section{Conclusions}

This study has systematically evaluated the effect of corner fins on the aerodynamic characteristics of a square cylinder via wind tunnel tests and large eddy simulations. Three types of corner fin configurations, i.e. fitting fins only at the leading corners, fitting fins only at the trailing corners, and fitting fins at both leading and trailing corners were studied. The findings are summarized below, which have practical significances

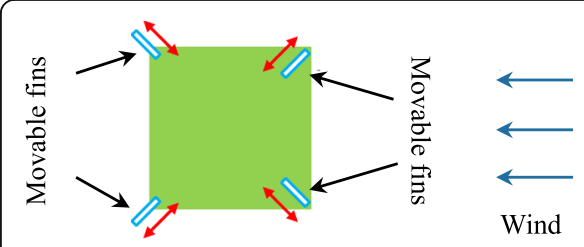

(a) Bridge pylons and tall building with movable fins

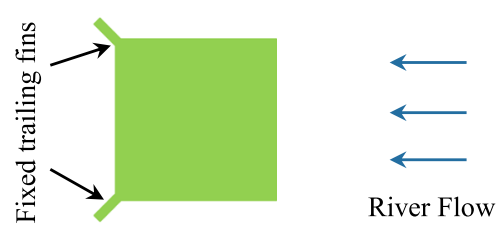

(b) Bridge pier with fixed trailing fins

Fig. 13 Two potential applications of the trailing fin configuration for reducing flow-induced force. a Bridge pylons and tall building with movable fins. $\mathbf{b}$ Bridge pier with fixed trailing fins 
for both reducing flow-induced vibration of civil structures including bridge pylons and tall buildings, and enhancing flow-induced vibration for harvesting energy.

The corner fins exhibit a remarkable influence on the surface pressure of the square cylinder and hence its aerodynamic force. Specifically, the leading fins enhance the suction on both side faces and leeward face, while the trailing fins weaken the suction on these faces. This interesting finding provides an effective aerodynamic strategy to control the cladding pressure of tall buildings or other square-sectioned bluff bodies. Meanwhile, the leading fins increase mean drag substantially while the trailing fins reduce the mean drag less significantly. The four fin case exhibits a resultant effect of leading fins and trailing fins, and it has a larger mean drag than the plain cylinder and a lower mean drag than the leading fin case. Similar to the effects of the fins on the mean drag, the leading fins increase the RMS lift coefficient significantly, whereas the trailing fins decrease the coefficient remarkably. In addition, the leading fins lead to an obviously lower vortex shedding frequency but much higher energy in the lift force spectrum, while the trailing fins result in a slightly lower frequency but much lower spectrum energy.

For the leading fin case, the larger curvature of the shear layer leads to larger suctions on both the side face and the leeward face than those of the plain cylinder, and hence a larger mean drag coefficient. Meanwhile, the separated shear layer has a stronger interaction with the side faces, which causes a larger fluctuating lift coefficient and a higher spectrum energy in the lift force spectrum.

For the trailing fin case, the recirculation zone is much longer than that of the plain cylinder and the shear layer is much less curved. The much less curved shear layer leads to less suctions on/beside the side faces and the leeward face, and hence a lower mean drag coefficient. The less fluctuating lift coefficient can also be attributed to the elongated wake recirculation zone. The trailing fins push the separated shear layer away and weakens its interaction with the side faces. The weaker interaction causes a lower spectrum peak in the lift force spectrum. The four fin case is believed to be a resultant of the leading fin case and the trailing fin case.

Although this study has systematically investigated the effect of corner fins on the aerodynamic characteristics of a square cylinder via both wind tunnel tests and large eddy simulations, it is worth devoting more efforts on this topic to further understand the effects due to its practical significance. For example, to understand the fluid-structure interaction behavior of a square cylinder with corner fins, it is suggested to perform aeroelastic tests in a wind tunnel or conduct numerical simulations with moving mesh. On the other hand, advanced experimental techniques, e.g. particle image velocimetry, can be used to visualize the flow field around a square cylinder with corner fins.

Abbreviations

LES: Large eddy simulations; RANS: Reynolds-averaged Navier-Stokes

\section{Acknowledgements}

The authors gratefully acknowledge the supports from National Key R\&D Program of China (2019YFC0810702) and Shenzhen Basic Research Program (JCYJ20170811160652645).

\section{Authors' contributions}

Qiulei Wang: Formal analysis, Investigation, Validation, Writing - original draft and review \& editing. Qi Jiang: Formal analysis, Methodology, Validation, Writing - original draft. Gang Hu: Conceptualization, Methodology, Investigation,

Formal analysis, Writing - original draft. Xiao Chen: Investigation, Writing - original draft. Chao Li: Methodology, Writing - review \& editing, funding secure. Yiqing Xiao: Conceptualization, Methodology, Supervision, funding secure, Writing review \& editing. The author(s) read and approved the final manuscript. 


\section{Funding}

National Key R\&D Program of China (2019YFC0810702) and Shenzhen Basic Research Program (JCYJ20170811160652645).

\section{Availability of data and materials}

No objection for data sharing.

\section{Declarations}

\section{Competing interests}

No competing interests.

Received: 16 December 2020 Accepted: 27 April 2021

Published online: 10 June 2021

\section{References}

Bao Y, Li H (2020) Machine learning paradigm for structural health monitoring. Struct Health Monit November:1-20

Bearman PW (1965) Investigation of the flow behind a two-dimensional model with a blunt trailing edge and fitted with splitter plates. J Fluid Mech 21(02):241-255. https://doi.org/10.1017/S0022112065000162

Bearman PW (1967) The effect of base bleed on the flow behind a two-dimensional model with a blunt trailing edge. Aeronaut Q 18(3):207-224. https://doi.org/10.1017/S0001925900004212

Bearman PW, Obasaju ED (1982) An experimental study of pressure fluctuations on fixed and oscillating square-section cylinders. J Fluid Mech 119:297-321. https://doi.org/10.1017/S0022112082001360

Bearman PW, Trueman DM (1972) An investigation of the flow around rectangular cylinders. Aeronaut Q 23(3):229-37

Blocken B (2014) 50 years of computational wind engineering: past, present and future. J Wind Eng Ind Aerodyn 129:69-102. https://doi.org/10.1016/j.jweia.2014.03.008

Breuer M, Bernsdorf J, Zeiser T, Durst F (2000) Accurate computations of the laminar flow past a square cylinder based on two different methods: lattice-Boltzmann and finite-volume. Int J Heat Fluid Flow 21(2):186-196. https://doi.org/10.1016/ S0142-727X(99)00081-8

Cao Y, Tamura T (2016) Large-eddy simulations of flow past a square cylinder using structured and unstructured grids. Comput Fluids 137:36-54. https://doi.org/10.1016/j.compfluid.2016.07.013

Carassale L, Freda A, Marrè-Brunenghi M (2014) Experimental investigation on the aerodynamic behavior of square cylinders with rounded corners. J Fluids Struct 44:195-204. https://doi.org/10.1016/j.jluidstructs.2013.10.010

Chen WL, Gao DL, Yuan WY, Li H, Hu H (2015) Passive jet control of flow around a circular cylinder. Exp Fluids 56:1-15

Ding F, Kareem A (2020) Tall buildings with dynamic facade under winds. Engineering 6(12):1443-1453. https://doi.org/10.101 6/j.eng.2020.07.020

Fan D, Yang L, Wang Z, Triantafyllou MS, Karniadakis GE (2020) Reinforcement learning for bluff body active flow control in experiments and simulations. PNAS 117(42):26091-26098. https://doi.org/10.1073/pnas.2004939117

Gao DL, Chen WL, Li H, Hu H (2017) Flow around a slotted circular cylinder at various angles of attack. Exp Fluids 58:1-15

Gousseau P, Blocken B, Van Heijst GJF (2013) Quality assessment of large-Eddy simulation of wind flow around a high-rise building: validation and solution verification. Comput Fluids 79:120-133. https://doi.org/10.1016/j.compfluid.2013.03.006

Hangan H (1996) Wake aerodynamics for 2D bluff bodies. The University of Western Ontario, Ontario

Haque MN, Katsuchi H, Yamada H, Nishio M (2014) Investigation of flow fields around rectangular cylinder under turbulent flow by les. Eng Appl Comput Fluid Mech 8:396-406

He GS, Li N, Wang JJ (2014) Drag reduction of square cylinders with cut-corners at the front edges. Exp Fluids 55(6):1-11 Holmes JD (2015) Wind loading of structures, 3rd edn. CRC Press, London

Hu G, Hassanli S, Kwok KCS, Tse KT (2017) Wind-induced responses of a tall building with a double-skin façade system. J Wind Eng Ind Aerodyn 168:91-100. https://doi.org/10.1016/j.jweia.2017.05.008

Hu G, Kwok KCS (2020) Predicting wind pressures around circular cylinders using machine learning techniques. J Wind Eng Ind Aerodyn 198:104099. https://doi.org/10.1016/j.jweia.2020.104099

Hu G, Liu F, Li L, Li C, Xiao Y, Kwok KCS (2019a) Wind energy harvesting performance of tandem circular cylinders with triangular protrusions. J Fluids Struct 91:102780. https://doi.org/10.1016/j.jluidstructs.2019.102780

Hu G, Liu L, Tao D, Song J, Tse KT, Kwok KCS (2020) Deep learning-based investigation of wind pressures on tall building under interference effects. J Wind Eng Ind Aerodyn 201:104138. https://doi.org/10.1016/j.jweia.2020.104138

Hu G, Song J, Hassanli S, Ong R, Kwok KCS (2019b) The effects of a double-skin façade on the cladding pressure around a tall building. J Wind Eng Ind Aerodyn 191:239-251. https://doi.org/10.1016/j.jweia.2019.06.005

Hu G, Tse KT, Kwok KCS (2016a) Enhanced performance of wind energy harvester by aerodynamic treatment of a square prism. Appl Phys Lett 108(12):123901. https://doi.org/10.1063/1.4944555

Hu G, Tse KT, Kwok KCS (2016b) Aerodynamic mechanisms of galloping of an inclined square cylinder. J Wind Eng Ind Aerodyn 148:6-17. https://doi.org/10.1016/j.jweia.2015.10.011

Hu G, Tse KT, Kwok KCS, Song J, Lyu Y (2016c) Aerodynamic modification to a circular cylinder to enhance the piezoelectric wind energy harvesting. Appl Phys Lett 109(19):193902. https://doi.org/10.1063/1.4967497

Hu G, Tse KT, Kwok KCS, Zhang Y (2015) Large eddy simulation of flow around an inclined finite square cylinder. J Wind Eng Ind Aerodyn 146:172-184. https://doi.org/10.1016/j.jweia.2015.08.008

Hu G, Tse KT, Wei M, Naseer R, Abdelke A, Kwok KCS (2018) Experimental investigation on the efficiency of circular cylinderbased wind energy harvester with different rod-shaped attachments. Appl Energy 226:682-689. https://doi.org/10.1016/ j.apenergy.2018.06.056

Hu G, Wang J, Su Z, Li G, Peng H, Kwok KCS (2019c) Performance evaluation of twin piezoelectric wind energy harvesters under mutual interference. Appl Phys Lett 115(7):073901. https://doi.org/10.1063/1.5109457

Huot JP, Rey C, Arbey H (1986) Experimental analysis of the pressure field induced on a square cylinder by a turbulent flow. $J$ Fluid Mech 162:283. https://doi.org/10.1017/S0022112086002057 
Jin X, Cheng P, Chen WL, Li H (2018) Prediction model of velocity field around circular cylinder over various Reynolds numbers by fusion convolutional neural networks based on pressure on the cylinder. Phys Fluids 30(4):047105. https:// doi.org/10.1063/1.5024595

Kawai H (1998) Effect of corner modifications on aeroelastic instabilities of tall buildings. J Wind Eng Ind Aerodyn 74:719-729

Kurata M, Ueda Y, Kida T, Iguchi M (2009) Drag reduction due to cut-corners at the front-edge of a rectangular cylinder with the length-to-breadth ratio being less than or equal to unity. J Fluids Eng 131:2-6

Kwok KCS, Bailey PA (1987) Aerodynamic devices for tall buildings and structures. J Eng Mech 113(3):349-365. https://doi. org/10.1061/(ASCE)0733-9399(1987)113:3(349)

Kwok KCS, Wilhelm PA, Wilkie BG (1988) Effect of edge configuration on wind-induced response of tall buildings. Eng Struct 10(2):135-140. https://doi.org/10.1016/0141-0296(88)90039-9

Lam K, Lin YF (2008) Large eddy simulation of flow around wavy cylinders at a subcritical Reynolds number. Int I Heat Fluid Flow 29(4):1071-1088. https://doi.org/10.1016/ji.jheatfluidflow.2008.01.006

Lam K, Lin YF, Zou L, Liu Y (2012) Numerical study of flow patterns and force characteristics for square and rectangular cylinders with wavy surfaces. J Fluids Struct 28:359-377. https://doi.org/10.1016/j.jluidstructs.2011.11.006

Laneville A, Gartshore I, Parkinson G (1975) An explanation of some effects of turbulence on bluff bodies. In: Proc. 4th Int. Conf. Wind Eff. Build. Struct

Lee BE (1975) The effect of turbulence on the surface pressure field of a square prism. J Fluid Mech 69(2):263-282. https:// doi.org/10.1017/S0022112075001437

Li C, Zhu S, Xu Y-L, Xiao Y (2013) 2.5D large eddy simulation of vertical axis wind turbine in consideration of high angle of attack flow. Renew Energy 51:317-330

Li M, Li S, Liao H, Zeng J, Wang Q (2016) Spanwise correlation of aerodynamic forces on oscillating rectangular cylinder. J Wind Eng Ind Aerodyn 154:47-57. https://doi.org/10.1016/j.jweia.2016.04.003

Li S, Laima S, Li H (2018) Data-driven modeling of vortex-induced vibration of a long-span suspension bridge using decision tree learning and support vector regression. J Wind Eng Ind Aerodyn 172:196-211. https://doi.org/10.1016/j.jweia.2017.10.022

Li S, Li M, Liao H (2015) The lift on an aerofoil in grid-generated turbulence. J Fluid Mech 771:16-35. https://doi.org/10.1017/ jfm.2015.162

Lim HC, Thomas TG, Castro IP (2009) Flow around a cube in a turbulent boundary layer: LES and experiment. J Wind Eng Ind Aerodyn 97(2):96-109. https://doi.org/10.1016/j.jweia.2009.01.001

Liu Z (2012) Investigation of flow characteristics around square cylinder with inflow turbulence. Eng Appl Comput Fluid Mech 6:426-446

Lyn DA, Einav S, Rodi W, Park J-H (1995) A laser-Doppler velocimetry study of ensemble-averaged characteristics of the turbulent near wake of a square cylinder. J Fluid Mech 304:285-319. https://doi.org/10.1017/S0022112095004435

Lyn DA, Rodi W (1994) The flaping shear layer formed by flow separation from the forward corner of a square cylinder. J Fluid Mech 267:353-376. https://doi.org/10.1017/S0022112094001217

Maskell EC (1965) A theory of blockage effects on bluff bodies and stalled wings in a closed wind tunnel. Her Majesty's Stationery Office, London

Modi V, El-Sherbiny S (1973) On the wall confinement effects in industrial aerodynamics studies. In: Proc. Int. Symp. Vib

Murakami S, lizuka S, Ooka R (1999) CFD analysis of turbulent flow past square cylinder using dynamic LES. J Fluids Struct 13(7-8):1097-1112. https://doi.org/10.1006/jls.1999.0246

Nakamura Y, Hirata K, Urabe T (1991) Galloping of rectangular cylinders inthe presence of a splitter plate. J Fluids Struct 5(5): 521-549. https://doi.org/10.1016/S0889-9746(05)80004-0

Nakayama A, Vengadesan SN (2002) On the influence of numerical schemes and subgrid-stress models on large eddy simulation of turbulent flow past a square cylinder. Int J Numer Methods Fluids 38(3):227-253. https://doi.org/10.1002/fld.214

Noel J, Yadav R, Li G, Daqaq MF (2018) Improving the performance of galloping micro-power generators by passively manipulating the trailing edge. Appl Phys Lett 083503:1-6

Ota T, Okamoto Y, Yoshikawa H (1994) A correction formula for wall effects on unsteady forces of 2-dimensional bluff-bodies. J Fluids Eng ASME 116(3):414-418. https://doi.org/10.1115/1.2910292

Otsuki Y, Fujii K, Washizu KT, Ohya A (1978) Wind tunnel experiments on aerodynamic forces and pressure distributions of rectangular cylinders in a uniform flow. In: Proceedings of the fifth symposium on wind effects on structures, pp 169-176

Rabault J, Kuchta M, Jensen A, Réglade U, Cerardi N (2019) Artificial neural networks trained through deep reinforcement learning discover control strategies for active flow control. J Fluid Mech 865:281-302. https://doi.org/10.1017/jfm.2019.62

Raju KGR, Singh V (1975) Blockage effects on drag of sharp-edged bodies. J Wind Eng Ind Aerodyn 1:301-309. https://doi. org/10.1016/0167-6105(75)90023-9

Ricciardelli $F$ (2010) Effects of the vibration regime on the spanwise correlation of the aerodynamic forces on a 5:1 rectangular cylinder. J Wind Eng Ind Aerodyn 98(4-5):215-225. https://doi.org/10.1016/j.jweia.2009.10.017

Rodi W (1997) Comparison of LES and RANS calculations of the flow around bluff bodies. J Wind Eng Ind Aerodyn 69-71:55-75

Rodi W, Ferziger JH, Breuer H, Pourquié M (1997) Status of large eddy simulation: results of a workshop. J Fluids Eng Trans ASME 119(2):248-262. https://doi.org/10.1115/1.2819128

Sakamoto S, Murakami S, Mochida A (1993) Numerical study on flow past 2D square cylinder by large Eddy simulation: comparison between 2D and 3D computations. J Wind Eng Ind Aerodyn 50:61-68. https://doi.org/10.1016/0167-6105/93 190061-R

Sohankar A, Norberg C, Davidson L (1999) Simulation of three-dimensional flow around a square cylinder at moderate Reynolds numbers. Phys Fluids 11(2):288-306. https://doi.org/10.1063/1.869879

Song J, Hu G, Tse KT, Li SW, Kwok KCS (2017) Performance of a circular cylinder piezoelectric wind energy harvester fitted with a splitter plate. Appl Phys Lett 223903:1-5

Tamura T, Miyagi T (1999) The effect of turbulence on aerodynamic forces on a square cylinder with various corner shapes. J Wind Eng Ind Aerodyn 83(1-3):135-145. https://doi.org/10.1016/S0167-6105(99)00067-7

Tang H, Shum KM, Li Y (2019) Investigation of flutter performance of a twin-box bridge girder at large angles of attack. J Wind Eng Ind Aerodyn 186:192-203. https://doi.org/10.1016/j.jweia.2019.01.010

Tombazis N, Bearman PW (1997) A study of three-dimensional aspects of vortex shedding from a bluff body with a mild geometric disturbance. J Fluid Mech 330:85-112. https://doi.org/10.1017/S0022112096003631 
Tominaga Y, Mochida A, Murakami S, Sawaki S (2008) Comparison of various revised k- $\varepsilon$ models and LES applied to flow around a high-rise building model with 1:1:2 shape placed within the surface boundary layer. J Wind Eng Ind Aerodyn 96(4):389-411. https://doi.org/10.1016/j.jweia.2008.01.004

Tse KT, Hitchcock PA, Kwok KCS, Thepmongkorn S, Chan CM (2009) Economic perspectives of aerodynamic treatments of square tall buildings. J Wind Eng Ind Aerodyn 97(9-10):455-467. https://doi.org/10.1016/j.jweia.2009.07.005

Voke PR (1997) Flow past a square cylinder: test case LES2. In: Chollet J-P (ed) Direct and large Eddy simulation II, proceedings of the ERCOFTAC workshop. Kluwer Academic Publishers, Grenoble, pp 355-373. https://doi.org/10.1007/ 978-94-011-5624-0_33

Xu F, Chen WL, Xiao YQ, Li H, Ou JP (2014) Numerical study on the suppression of the vortex-induced vibration of an elastically mounted cylinder by a traveling wave wall. J Fluids Struct 44:145-165. https://doi.org/10.1016/j.jfluidstructs.2 013.10 .005

Yan B, Li Q (2016) Large-eddy simulation of wind effects on a super-tall building in urban environment conditions. Struct Infrastruct Eng 12(6):765-785. https://doi.org/10.1080/15732479.2015.1051997

Zhang W, Samtaney R (2016) Low-re flow past an isolated cylinder with rounded corners. Comput Fluids 136:384-401. https://doi.org/10.1016/j.compfluid.2016.06.025

Zheng D-q, Zhang A-s, Gu M (2012) Improvement of inflow boundary condition in large eddy simulation of flow around tall building. Eng Appl Comput Fluid Mech 6:633-647

\section{Publisher's Note}

Springer Nature remains neutral with regard to jurisdictional claims in published maps and institutional affiliations.

Submit your manuscript to a SpringerOpen ${ }^{\odot}$ journal and benefit from:

- Convenient online submission

- Rigorous peer review

- Open access: articles freely available online

High visibility within the field

- Retaining the copyright to your article

Submit your next manuscript at $\boldsymbol{\nabla}$ springeropen.com 